\title{
INFLUENCE OF KRAFT LIGNIN ON THE PROPERTIES OF RUBBER COMPOSITES
}

\author{
Matshidiso Makhalema ${ }^{1}$, Percy Hlangothi ${ }^{1}$, Setumo Victor Motloung ${ }^{2,3}$ \\ Lehlohonolo Fortune $\mathrm{KoaO}^{4}$, Tshwafo Elias Motaung ${ }^{3,5}$ \\ 1Nelson Mandela University, South Africa \\ 2Walter Sisulu University \\ 3Sefako Makgatho Health Sciences University, South Africa \\ ${ }^{4}$ University of The Free State, South Africa \\ 5University of South Africa, South Africa
}

(Received June 2020)

\begin{abstract}
The influence of lignin content on reclaimed rubber (RR)/natural rubber (NR) blend composite properties has successfully been studied. Scanning electron microscopy (SEM) were used to understand morphology. Fourier-transform infrared spectroscopy (FTIR) for the possible chemical interaction, whereas thermogravimetric analysis (TGA) and tensile tester were used to predict strength and elongation for possible practical applications. The results indicated that the presence of lignin forms cavities which seemed to arise from complex interactions of the blend with the lignin. Those cavities dominated tensile fractured surface and the increase in lignin indicated inconsistencies of interfacial interactions. Lignin RR/NR blend composites revealed a drop in tensile strength and shift in glass transition temperature, except for the highest lignin containing blend composite. More active interactive constituent of the blend appeared to be NR. The interaction has not favored the thermal stability and crosslinking density.
\end{abstract}

KEYWORDS: Blend composites, polymer composites, lignin, biomass, lignin-polymer composites.

\section{INTRODUCTION}

Recently, there has been renewed interests in the utilization of lignocellulosic components such as cellulose lignin and hemicellulose to advance green applications of materials (Mohomane et al. 2017, Sibiya et al. 2018). Some researchers compared modified characteristics of celluloses from different sources (Linganiso et al. 2019), whereas some tested potential of the modified surfaces in different polymeric matrices (Sibiya et al. 2018). Of more interest 
is the employment of lignin, a complex, amorphous-thermoplastic material as a filler, modifier and reinforce in polymeric materials such as rubbers and plastics. Due to its abundance and versatility compared to inorganic fillers, lignin has gained a lot of attention (Datta et al. 2017, Frigerio et al. 2014, Yu et al. 2015, Liu et al. 2015, Botros et al. 2005, Barana et al. 2016, Sen et al. 2015). Lignin has been reported to have interesting properties which include flame retardant abilities, antioxidative characteristics, biodegradability, antimicrobial behaviour and adhesive capabilities. Furthermore, the structure of lignin contains a variety of chemical functional groups that positively influence its reactivity, making it able to meet the needs of most rubber industries (Sen et al. 2015, Setua et al. 2000, Jiang et al. 2014, Košíková et al. 2007, Košíková et al. 2005, Gregorová et al. 2006, Kumaran et al. 1978).

A lot of research has been done on the incorporation cellulose to formulate composites that could be applied industrially. For instance, Che et al. (2018) utilized a water-soluble copolymer for wood modification, while Furuno et al. (2004), Klüppel and Mai (2013), Yu et al. (2011) small molecular sizes, low molecular weight urea formaldehyde and phenol formaldehyde resins. Those materials can effectively penetrate through wood micropores and grafting and/or crosslinking with wood cells to enhance the dimensional stability and other properties of wood. Lignin is one component of lignocellulosic material which also received fair attention as a filler in polymer blends. For instance, as a filler in natural rubber (NR) Yu et al. (2015), Setua et al. (2000), Jiang et al. (2014) and Košíková et al. (2005, 2007) studied NR composites filled with sulphur-free lignin under sulphur vulcanization. The addition of lignin up to $30 \mathrm{phr}$ into the NR rubber composites resulted in improved physico-mechanical properties such as $100 \%$ increment in modulus, elongation at break and tensile strength. It was also reported that lignin influenced the cure characteristics (increased scorch time and decreased optimum cure time) of the NR compounds. They further demonstrated that the significant improvement in the study was observed when the NR was filled with $20 \mathrm{phr}$ lignin. This observed positive effect on the mechanical properties of NR vulcanizates was attributed to the relatively low molecular mass and polydispersity of the lignin which allowed for a good lignin-NR miscibility. Similar results were observed by Gregorová et al. (2006). They argued that the lignin influences the retention of physico-mechanical properties of non-aged natural rubber system in the small concentrations. Setua et al. (2000) also showed that reinforcing nitrile rubber with modified lignin resulted in better thermal stability when compared against phenolic resins or carbon black. It was shown that lignin is a more capable replacement to the costlier petroleum derived carbon black and phenolics subsequently imparting on the lignin-rubber composite superior oil resistance. Košíková et al. (2007) has demonstrated through SEM micrographs, the morphological properties of NR vulcanizates with and without lignin which showed that lignin enhanced the dispersion of other compounding ingredients in the mix.

There is little or/and no information regarding the influence of lignin on the blend of reclaimed rubber (RR)/ natural rubber (NR). The novelty of this study is based on systematic incorporation of lignin in the blend. The blend composites were analyzed by scanning electron microscopy (SEM), Fourier transform infrared spectroscopy (FTIR) thermogravimetric analysis (TGA) and tensile tester.

\section{MATERIAL AND METHODS}

\section{Materials}

Kraft (alkali) lignin in the form of brown powder, was obtained from Sigma Aldrich, South Africa. It has average molecular weight of about 10 000. Reclaimed rubber was obtained 
from EnvanDe Rubber, Pietermaritzburg, South Africa. It has specific gravity of 1.15, tensile strength of and elongation at break of natural rubber (SMR 20) was obtained from S\&N Rubber, Port Elizabeth, South Africa.

\section{Preparation of blends and composites}

All samples were prepared by twin roll mill at room temperature for $15 \mathrm{~min}$ before hydraulic pressing into sheets. The blend homogeneity was achieved at about $15 \mathrm{~min}$ prior lignin addition, at which the time counting of mixing blend composites was started. Preliminary results recommend 90:10 ratio due to homogeneity as confirmed in literature (Sen et al. 2015, Kumaran et al. 1978, Tibenham et al. 1954). A mixture design was used to formulate the different blend composites as shown in Tab. 1 below.

Tab. 1: Formulations used in preparation of lignin-rubber blends and composites by mixed design.

\begin{tabular}{lccc} 
Abbreviations & Reclaimed rubber $(\mathrm{g})$ & Natural rubber(g) & Lignin (\%) \\
\hline RR/NR blend & 90 & 10 & 0 \\
$10 \mathrm{pphr}$ & 90 & 10 & 10 \\
$20 \mathrm{pphr} \mathrm{o}$ & 90 & 10 & 20 \\
$30 \mathrm{pphr}$ & 90 & 10 & 30 \\
\hline
\end{tabular}

\section{Scanning electron microscopy (SEM)}

Morphological analysis of the composites was characterised by SEM. The micrographs were taken using an FEI Quanta 200 (FEI Co., Eindhoven, the Netherlands) electron microscope operated at an accelerating voltage of $15 \mathrm{kV}$. All samples were fractured in liquid nitrogen, sputter-coated with gold and allowed to dry before taking images.

\section{Fourier-transform infrared spectroscopy (FTIR)}

The FTIR spectra were collected by using a Perkin Elmer FTIR spectrometer in the diffuse reflectance mode. The samples were analysed in the spectral region between 4000 and $400 \mathrm{~cm}^{-1}$ with a $4 \mathrm{~cm}^{-1}$ resolution.

\section{Thermogravimetric analysis (TGA)}

Thermogravimetric analyses were performed using TGA analyser unit (Perkin Elmer), under flowing nitrogen atmosphere at flow rate of $20 \mathrm{ml} \cdot \mathrm{min}^{-1}$. Approximately $10-15 \mathrm{mg}$ of sample was heated from $30^{\circ} \mathrm{C}$ to $700^{\circ} \mathrm{C}$ at a heating rate of $10^{\circ} \mathrm{C} \mathrm{min}-1$.

\section{Dynamic mechanical analysis (DMA)}

The dynamic mechanical analysis (DMA) Q800 of the PP and composites were investigated from 40 to $180^{\circ} \mathrm{C}$ by 3 -point bending mode with $15 \mathrm{~mm}$ sample size at a heating rate of $5^{\circ} \mathrm{C} \cdot \mathrm{min}^{-1}$ and a frequency of $1 \mathrm{~Hz}$.

\section{Tensile testing}

Measurements of tensile strength were carried out on three dumb-bell shaped samples, width of $1 \mathrm{~mm}$ using a Universal Testing Machine QC 505 with a crosshead speed of $500 \mathrm{~mm} \cdot \mathrm{min}^{-1}$ and a $500 \mathrm{~N}$ load cell. Median values of at least 5 samples per test were used for data analysis

\section{Swelling experiments}

Swelling was studied in toluene according to ASTM D 471-79. A sorption-desorption 
method was used to determine the swelling behavior of the rubber samples; this being demonstrated as the mole percent uptake of toluene by a gram of rubber at room temperature. The rubber sample was cut into $20 \times 20 \mathrm{~mm}$ for measuring and calculation of swelling percentage.

\section{RESULTS AND DISCUSSION}

\section{Scanning electron microscopy (SEM)}

SEM micrographs of the tensile fractured surface of lignin RR/NR blend composites are shown in Fig. 1. The $10 \mathrm{pphr}$ (Fig. 1a) of lignin in the blend composite generally showed smaller pore sizes, compared to $20 \mathrm{pphr}$ (Fig. 1b) and $30 \mathrm{pphr}$ ( Fig. 1c), ranging from approximately 50 to $173 \mu \mathrm{m}$. Whereas $20 \mathrm{pphr}$ lignin indicated pore sizes ranging from approximately 70 to $400 \mu \mathrm{m}$. Surprisingly the pores generally seemed to reduce (most are smaller from 50 to $294 \mu \mathrm{m}$ ) in sizes for the $30 \mathrm{pphr}$ blend composites and the surface appeared rougher. In fact, there are clear potholes or pits in Figs. 1b,c which maybe an indication of a departure of a material during fracturing. There is a limited information on a study involving lignin blend with reclaimed rubber, however Ramarad et al. (2015) studied lignin reinforced rubber composites. Formation of pits, large cavities and grooves were dominating their tensile fractured surface. They related the observation to the interaction of alcohol and phenolic groups in lignin with mostly unvulcanised part of the rubber. The same explanation is highly possible in the current study, however the natural rubber seemed to be more interactive with lignin than the reclaimed rubber. In fact, this is logical because reclaiming rubber is known for reducing molecular weight and promotes a partial degradation that limit pendent groups for more interactions (Barana et al. 2016, Gregorová et al. 2006, Asrul et al. 2014). Therefore, some of pores may have resulted from an escape of natural rubber when interacting with the lignin.
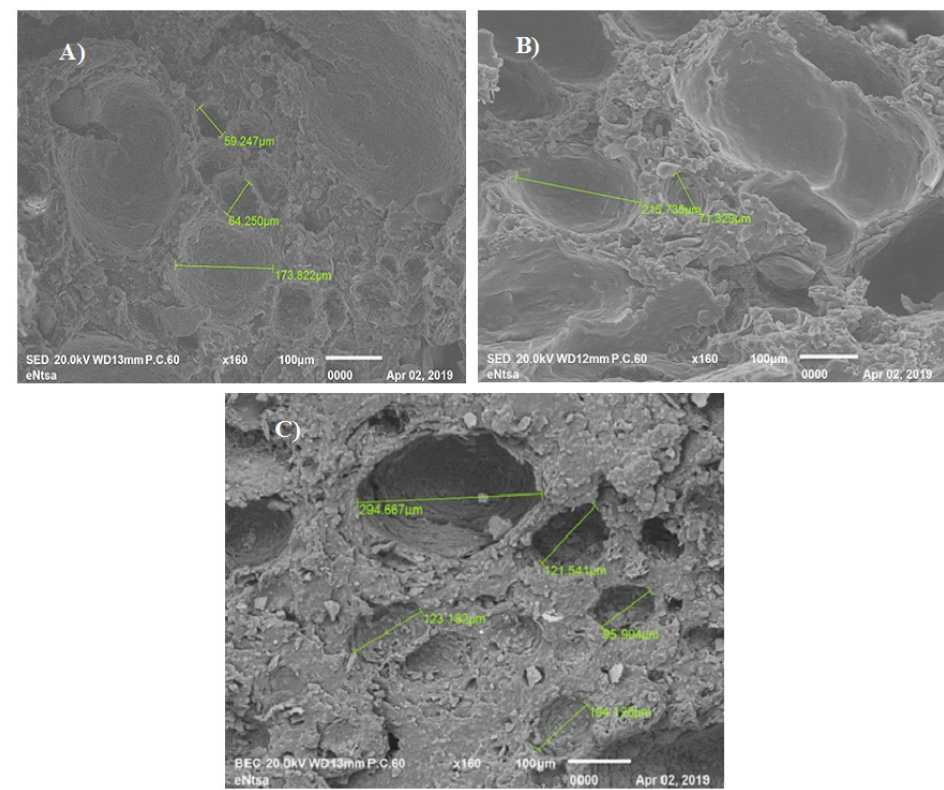

Fig. 1: SEM image of lignin RR/NR blend composites containing: a) 10 pphr, b) 20 pphr, and c) 30 pphr of lignin. 


\section{Fourier-transform infrared spectroscopy (FTIR)}

FTIR spectra of RR/NR blend and blend composites are presented in Fig. 2. The blend exhibited peaks at 3100-3000 $\mathrm{cm}^{-1}, 1596-1680 \mathrm{~cm}^{-1}$, and $1384-1000 \mathrm{~cm}^{-1}$ and a hump at $3400 \mathrm{~cm}^{-1}$ which are known for $\mathrm{CH}, \mathrm{C}=\mathrm{C}, \mathrm{C}-\mathrm{C}$ and $\mathrm{N}-\mathrm{H}$ vibrations respectively (Ramarad et al. 2015, Yu et al. 2015, Liu et al. 2010, Botros et al. 2005). The peaks are typical in literature for a blend of the two rubbers (Ismail et al. 2002). The presence of lignin in the blend generally led to inconsistent effect. For instance, $10 \mathrm{pphr}$ exhibited a suppression of $\mathrm{C}=\mathrm{C}$ vibrations that seemed to resurrect at highest lignin content. In fact, there are virtually double peaks at approximately $1384 \mathrm{~cm}^{-1}$ for all except for $10 \mathrm{pphr}$ containing blend composite. Nonetheless it could be convincing to consider the inconsistencies as the elements of interfacial interaction that promoted pores as seen from SEM.
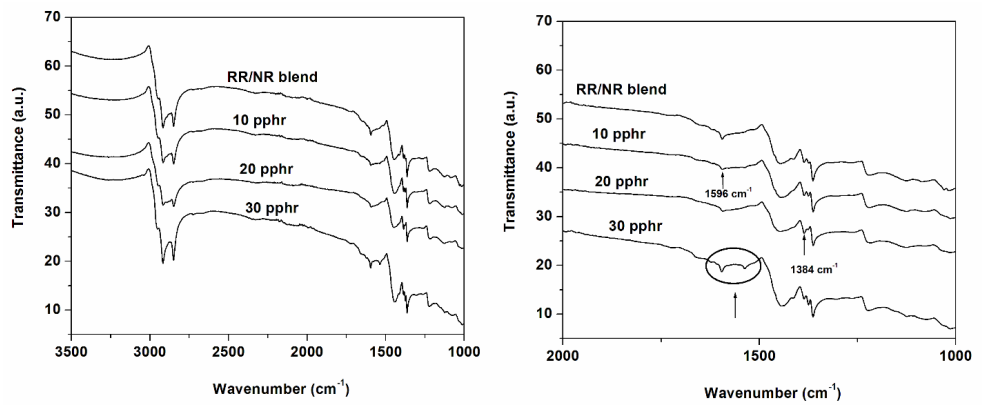

Fig. 2: FTIR spectra of RR/NR blend and lignin RR/NR blend composites.

\section{Thermal gravimetric analysis (TGA)}

Fig. 3 shows the TGA and DTG graphs of lignin RR/NR blend composites. The presence of lignin generally decreased the thermal stability of the composites.
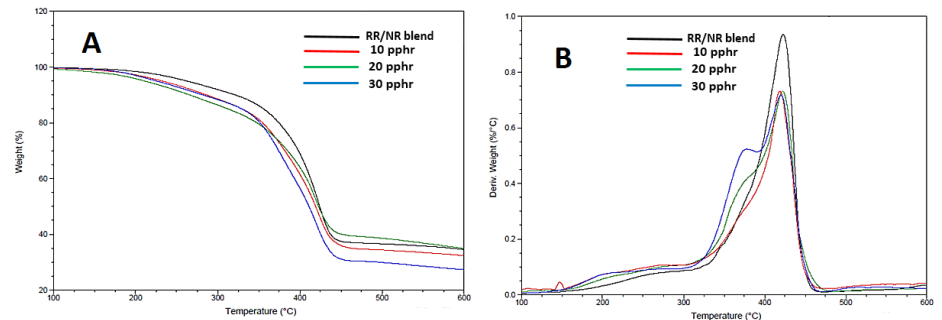

Fig. 3: $T G A(A)$ and $D T G(B)$ graphs of the lignin $R R / N R$ blend composites.

This observation is not extraordinary in literature as a presence of lignin in natural fibres is known for diminishing thermal stability of the fibres. In most cases researchers centralised the rational to phenolic content, low molecular weight and the origin of lignin thereof (Datta et al. 2017, Frigerio et al. 2014, Yu et al. 2015, Liu et al. 2010, Botros et al. 2005, Barana et al. 2016). But in our case, the interfacial interaction appeared to be promoted by compatibility of the lignin and the major phase (see SEM results Fig. 1b,c). That could account for the observed drop in thermal stability. There seems to be no clear order of the lignin content against thermal stability of the blend composites, nonetheless the $30 \mathrm{pphr}$ lignin RR/NR blend composite has 
shown lowest thermal stability and char content than the rest. It is worth noting that lignin has a potential to increase char content of the blend composites to almost equal that of the pure blend. In fact, irregular pore sizes and complex interfacial interaction of lignin and reclaimed rubber as confirmed by SEM and FTIR could account for the lack of order in both thermal stability and residual content.

\section{Mechanical properties}

The mechanical properties of the blend composites such as tensile strength, elongation at break and modulus were investigated. Fig. 4 shows that with increasing amount of lignin RR/NR blend composites revealed a drop in tensile strength, except for the highest lignin containing blend composite which has shown increased tensile strength that is even higher than of the pure blend composite by almost $40 \%$.

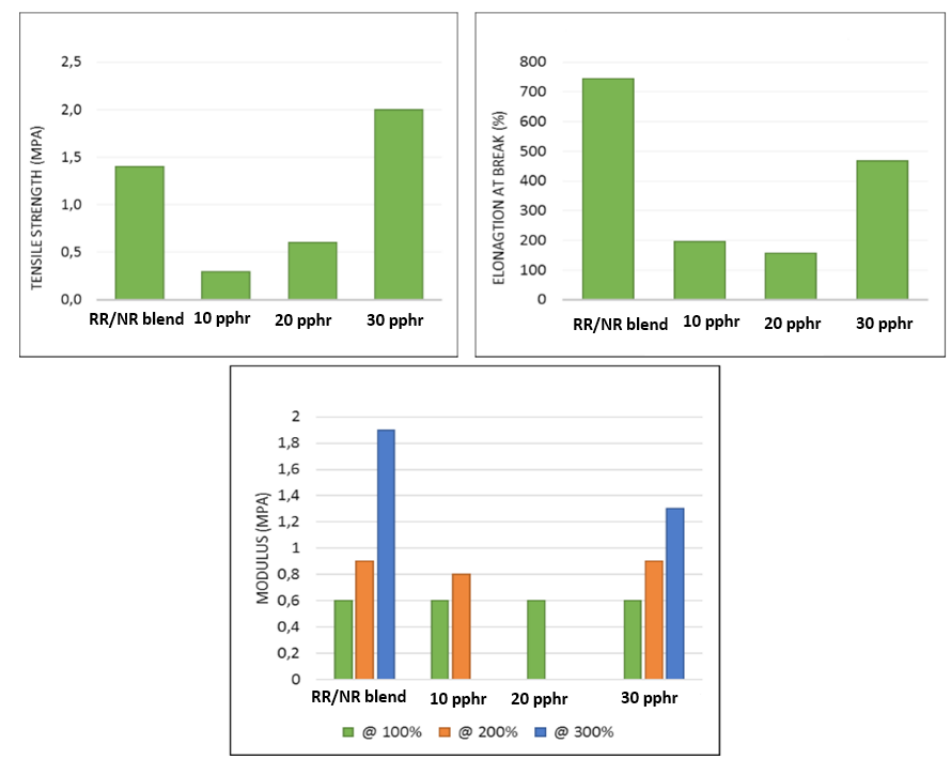

Fig. 4: Mechanical properties of the lignin RR/NR blend composites.

Almost the similar trend was also observed in the case of elongation at break, nonetheless in opposite direction for each content. For instance, the elongation at break of the clean blend composite decreased by more than $50 \%$ compared to 10 and $20 \mathrm{pphr}$ and almost $45 \%$ for $30 \mathrm{pphr}$ lignin containing blend composites. Moduli were measured at 100\%, 200\%, and $300 \%$, elongation. There was no much changes in modulus at $100 \%$ elongation, but at $300 \%$ elongation there was a surprise decrease in modulus of $30 \mathrm{pphr}$ blend composites compared to the clean blend. This could be the results of inconsistencies as the elements of interfacial interaction and formation of pores as confirmed by SEM and FTIR. In fact, such defects are known for promoting lowering molecular weight of NR to shorter segments for a reduced tensile strength in RR/NR blend composites (Premachandra et al. 2011, Datta et al. 2017, Frigerio et al. 2014, Yu et al. 2015, Liu et al. 2010). Therefore, it may be virtually fair in this study to regard lignin as a contributing agent that lowered molecular weight of NR to render reduced 
mechanical properties of the blend composites. Furthermore, SEM suggested the formation of the pores which are known for lowering a load transfer within the rubber matrix. In fact, Kumaran et al. (1978) explain it as a reduced elastic behavior of the elastomer by the addition of lignin.

\section{Dynamic mechanical analysis (DMA)}

The DMA analysis was used to characterize the dynamic mechanical behaviour of the prepared lignin rubber composites. The variation of tangent delta $(\tan \delta)$ and storage modulus $\left(\mathrm{E}^{\prime}\right)$ as a function of temperature are reported in Fig. 5.
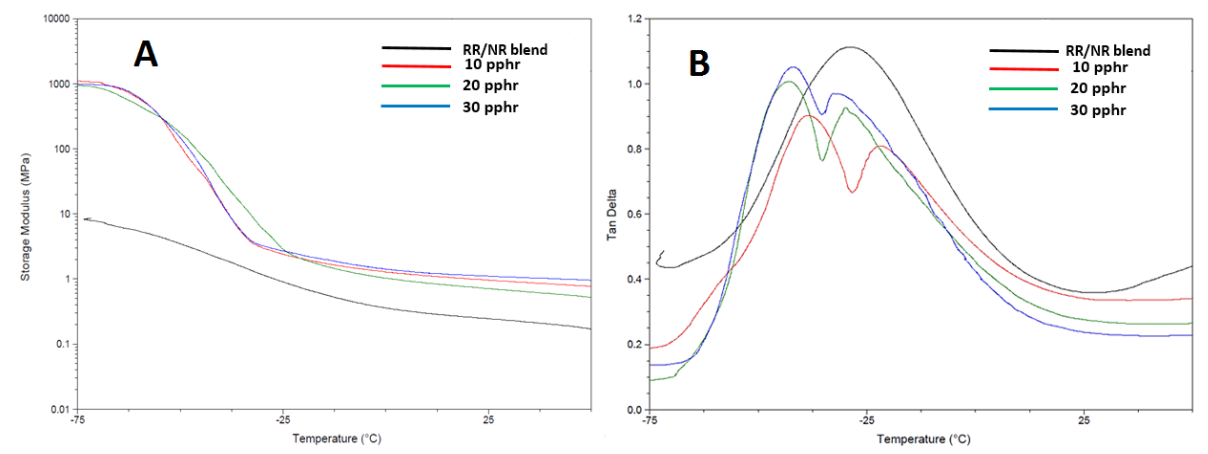

Fig. 5: Storage modulus and Tan $\delta$ curves of $R R-N R-L G$ composites.

The figure shows the influence of lignin on the storage modulus and damping of RR-NR blends. The addition of lignin resulted in the increase in storage modulus and that can be explained by reduced chain mobility due to the lignin addition. This is in agreement with the mechanical properties particularly the highest containing lignin composite that indicated increased storage modulus. As shown in Fig. 4 , the $\tan \delta$ curves revealed that the RR-NR-LG composites exhibit two glass transition temperatures. One occurring at low temperatures is associated to RR-NR blends and the second at high temperatures corresponds to the lignin. Both the $T_{g}$ s slightly shifted to higher temperatures with increasing lignin loading. Furthermore, it can be observed that the $\tan \delta$ peak values decreased each by approximately $10 \%$ with the increase in lignin content, suggesting a continuous decrease in rubber chain mobility and this is due to the strong interaction between the lignin and RR-NR matrix.

\section{Crosslink density}

Fig. 6 represents blend and lignin blend composites. The presence of lignin generally increased the crosslinking density except for the highest lignin containing blend composite.

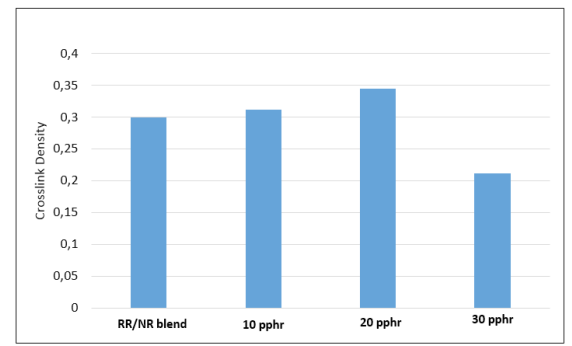

Fig. 6: Crosslinking density of the lignin $R R / N R$ blend composites. 
There was no much change in crosslinking density, nonetheless 30pphr blend composite revealed a decrease in the density by almost $40 \%$. For $20 \mathrm{pphr}$, the observed slight increase in crosslinking density could have emanated from the complex interaction of lignin with the crosslinking sites. This is could be confirmed by suppression of $\mathrm{C}=\mathrm{C}$ vibrations that seemed to revive at highest lignin content and disappearance of a peak observed from FTIR and/or cavities from SEM. It is recorded in literature that a material with a higher crosslinking density could have high thermal stability apparently due to crosslinking sites which delay a chain mobility (Ismail et al. 2002, Rattanasom et al. 2005, Yahya et al. 2011, Košíková et al. 2007). The explanation clarifies somehow TGA results in this study because it has the similar trend to crosslinking density. By the way modulus also has shown decline at $30 \mathrm{pphr}$. Perhaps lowering molecular weight of NR to shorter segments also confirms the loss of crosslinking site which rendered lower density ultimately.

\section{CONCLUSIONS}

The effect of the lignin on properties of reclaimed rubber/natural rubber blend composites were successfully prepared and investigated. SEM revealed clear pores which varied in sizes which according to FTIR emanated from the presence of the symmetric aromatic skeletal vibration by lignin macromolecules. Of course, the pores resulted into the general decrease in mechanical properties to almost $50 \%$ and crosslinking density of reclaimed rubber/natural rubber blend composites. On the other hand, the observation is a resilient proposal that the lignin could be a potential foam agent in the blend without a blowing agent. The presence of lignin has also resulted in a general decrease in thermal stability. In fact, is worth noting that lignin has a potential to increase char content of the blend composites significantly. The observed char content trend provokes some applications for flame retardants material.

\section{REFERENCES}

1. Brinchi, L., Cotana, F., Fortunati, E., Kenny, J.M., 2013: Production of nano-crystalline cellulose from lignocellulosic biomass: Technology and applications. Carbohydrates Polymers 94: 145-169.

2. Ramarad, S., Khalid, M., Ratnam, C.T., Chuah, A.L., Rashmi, W., 2015: Waste tire rubber in polymer blends: A review on the evolution, properties and future. Progress in Materials Science 72: 100-40.

1. Ismail, H., Nordin, R., Noor, A.M., 2002: Cure characteristics, tensile properties and swelling behaviour of recycled rubber powder-filled natural rubber compounds. Polymer Testing 21(5): 565-9.

2. Ismail, H., Nordin, R., Noor, A.M., 2003: The effects of recycle rubber powder content and various vulcanization systems on curing characteristics and mechanical properties of natural rubber/recycle rubber powder blend. Iranian Polymer Journal 12: 373-380.

3. Rattanasom, N., Poonsuk, A., Makmoon, T., 2005: Effect of curing system on the mechanical properties and heat aging resistance of natural rubber/tire tread reclaimed rubber blends. Polymer Testing 24(6): 728-32.

4. Hassan, M.M., Mahmoud, G.A., El-Nahas, H.H., Medhat, M., Ghada, A., Hussien, H., El-Sayed, A., Hegazy, H.A., 2007: Reinforced material from reclaimed rubber/natural rubber, using electron beam and thermal treatment. Journal of Applied Polymer Science 104(4): 2569-78. 
5. Premachandra, J.K., Edirisinghe, D.G., De Silva, M.I., 2011: A novel reclaiming agent for ground rubber tyre (GRT). Part 1: Property evaluation of virgin natural rubber (NR)/novel reclaimed GRT blend compounds. Progress in Rubber, Plastic and Recycling Technology 27(1): 31-48.

6. Sombatsompop, N., Kumnuantip, C., 2003: Rheology, cure characteristics, physical and mechanical properties of tire tread reclaimed rubber/natural rubber compounds. Journal of Applied Polymer Science 87(10): 1723-31.

7. Sreeja, T.D., Kutty, S.K., 2000: Cure characteristics and mechanical properties of natural rubber/reclaimed rubber blends. Polymer-Plastics Technology and Engineering 39(3): 50112.

8. Farahani, T.D., Bakhshandeh, G.R., Abtahi, M., 2006: Mechanical and viscoelastic properties of natural rubber/reclaimed rubber blends. Polymer Bulletin 56(4-5): 495-505.

9. Yahya, Y.R., Azura, A.R., Ahmad, Z., 2011: Effect of curing systems on thermal degradation behaviour of natural rubber (SMR CV 60). Journal of Physical Science 22(2): 1-4.

10. Valášek, P., Müller, M., Ružbarský, J., 2014: Using recycled rubber particles as filler of polymers. Applied Mechanics and Materials 616: 260-267.

11. Datta, J., Parcheta, P., Surówka, J., 2017: Softwood-lignin/natural rubber composites containing novel plasticizing agent: Preparation and characterization. Industrial Crops and Products 95: 675-85.

12. Frigerio, P., Zoia, L., Orlandi, M., Hanel, T., Castellani, L., 2014: Application of sulphur-free lignins as a filler for elastomers: effect of hexamethylenetetramine treatment. Bioresource Technology 9(1): 1387-400.

13. Yu, P., He, H., Jiang, C., Wang, D., Jia, Y., Zhou, L., Jia, D.M., 2015: Reinforcing styrene butadiene rubber with lignin-novolac epoxy resin networks. Express Polymer letters 9(1).

14. Liu, S., Cheng, X., 2010: Application of lignin as antioxidant in styrene butadiene rubber composite. AIP Conference Proceedings 1: 344-347.

15. Botros, S.H., Eid, M.A., Nageeb, Z.A., 2005: Thermal stability and dielectric relaxation of NR/soda lignin and NR/thiolignin composites. Egyptian Journal of Solids 28(1):1-67.

16. Barana, D., Ali, S.D., Salanti, A., Orlandi, M., Castellani, L., Hanel, T., Zoia, L., 2016: Influence of lignin features on thermal stability and mechanical properties of natural rubber compounds. ACS Sustainable Chemistry and Engineering 4(10): 5258-67.

17. Sen, S., Patil, S., Argyropoulos, D.S., 2015: Thermal properties of lignin in copolymers, blends, and composites: a review. Green Chemistry 17(11): 4862-87.

18. Setua, D.K., Shukla, M.K., Nigam, V., 2000: Lignin reinforced rubber composites. Polymer Composites 21(6): 988-995.

19. Jiang, C., He, H., Yao, X., Yu, P., Zhou, L., Jia, D., 2014: Self-crosslinkable lignin/epoxidized natural rubber composites. Journal of Applied Polymer Science 131(23).

20. Košíková, B., Gregorova, A., Osvald, A., Krajčovičová, J., 2005: Role of lignin filler in stabilization of natural rubber-based composites. Journal of Applied Polymer Science 103(2): 1226-31.

21. Košíková, B., Gregorová, A., 2005: Sulfur-free lignin as reinforcing component of styrene-butadiene rubber. Journal of Applied Polymer Science 97(3): 924-9.

22. Gregorová, A., Košíková, B., Moravčík, R., 2006: Stabilization effect of lignin in natural rubber. Polymer Degradation and Stability 91(2): 229-33.

23. Kumaran, M.G., De, S.K., 1978: Utilization of lignins in rubber compounding. Journal of Applied Science 22(7): 1885-93. 
24. Asrul, M., Othman, M., Zakaria, M., Nazir A.K., 2014: Morphology, tensile strength and oil resistance of gum rubber sheets prepared from lignin modified natural rubber. EDP Sciences Journals 13: 1-6.

25. Tibenham, F.J., Grace, N.S., 1954: Compounding natural rubber with lignin and humic acid. industrial and engineering chemistry 46(4): 824-8.

26. Chigondo, F., Shoko, P., Nyamunda, B.C., Guyo, U., Moyo, M., 2013: Maize stalk as reinforcement in natural rubber composites. International Journal of Scientific and Technology Research 2(6): 263-71.

27. Barana, D., Ali, S.D., Salanti, A., Orlandi, M., Castellani, L., Hanel T., Zoia, L., 2016: Influence of lignin features on thermal stability and mechanical properties of natural rubber compounds. ACS Sustainable Chemistry and Engineering 4(10): 5258-67.

28. Yu, P., He, H., Jia, Y., Tian, S., Chen, J., Jia, D., Luo, Y., 2016: A comprehensive study on lignin as a green alternative of silica in natural rubber composites. Polymer Testing 54: 176-85.

29. Tanasi, P., Santana, M.H., Carretero-González, J., López-Manchado, M.A., 2019: Thermo-reversible crosslinked natural rubber: A Diels-Alder route for reuse and selfhealing properties in elastomers. Polymer 175: 15-24.

30. De, D., Panda, P.K., Roy, M., Bhunia, S., 2013: Reinforcing effect of reclaim rubber on natural rubber/polybutadiene rubber blends. Materials and Design 46: 142-50.

31. Che, W., Xiao, Z., Han, G., Zheng, Z., Xie, Y., 2018: Radiata pine wood treatment with a dispersion of aqueous styrene/acrylic acid copolymer. Holzforschung 72(5): 387-396.

32. Furuno, T., Imamura, Y., Kajita, H., 2004: The modification of wood by treatment with low molecular weight phenol-formaldehyde resin: a properties enhancement with neutralized phenolic-resin and resin penetration into wood cell walls. Wood Science and Technology 37(5): 349-361.

33. Yu, X., Sun, D., Li, X., 2011: Preparation and characterization of urea-formaldehyde resinsodium montmorillonite intercalation-modified poplar. Journal of Wood Science 57(6): 501-506.

34. Klüppel, A., Mai, C., 2013: The influence of curing conditions on the chemical distribution in wood modified with thermosetting resins. Wood Science and Technology 47(3): 643658.

35. Mohomane, S.M., Linganiso, L.Z., Buthelezi, T., Motaung, T.E., 2017: Effect of extraction period on properties of sugarcane bagasse and softwood chips cellulose. Wood Research 62: 931-938.

36. Sibiya, N.N., Mochane, M.J., Motaung, T.E., Linganiso, L.Z., Hlangothi, S.P., 2018: Morphology and properties of sugarcane bagasse cellulose- natural rubber composites. Wood Research 63: 821-832.

37. Linganiso, L.Z., Buthelezi ,T., Motaung ,T.E., 2019: A comparative study of sugarcane bagasse and soft wood. Wood Research 64: 273-28.

\author{
Matshidiso Makhalema, Percy Hlangothi \\ Nelson Mandela Metropolitan University \\ Department of Chemistry \\ P.O. Box 77000 \\ Port Elizabeth 603I \\ South Africa
}




\author{
Setumo V. Motloung \\ Sefako Makgatho Health Sciences University \\ Department of Physics \\ P.O. Box 94, Medunsa 0204 \\ South Africa \\ Walter Sisulu University \\ Department of Chemical and Physical Sciences \\ Private Bag Xi, Mthatha Campus, UNITRA 5 II 7 \\ South Africa \\ Lehlohonolo Koao \\ University of The Free State (Qwaqwa Campus) \\ Department of Physics \\ Private Bag Xi3 3 , Phuthaditjhaba 9866 \\ South Africa \\ Tshwafo E. Motaung* \\ University of South Africa \\ Department of Chemistry \\ School of Science in The College of Science \\ EngineERING ANd Technology \\ University of South Africa \\ Preller Street, Muckleneuk Ridge, City of Tshwane \\ P.O. Box 392, UNISA 0003 \\ South Africa \\ Sefako Makgatho Health Sciences University \\ Department of Chemistry \\ P.O. Box 94, Medunsa 0204 \\ South Africa
}

*Corresponding author: motaungte@live.com 
